Short communication

\title{
Development and validation of RP-HPLC-UV method for the determination of Glipizide in human plasma
}

\author{
M. Atif ${ }^{\mathrm{a}, *}$, S.H. Khalid ${ }^{\mathrm{b}}$, G.L. Onn Kit ${ }^{\mathrm{b}}$, S.A.S. Sulaiman ${ }^{\mathrm{a}}$, M. Asif $^{\mathrm{c}}$, A. Chandersekaran $^{\mathrm{d}}$ \\ a Discipline of Clinical Pharmacy, School of Pharmaceutical Sciences, Universiti Sains Malaysia, Penang, Malaysia \\ ${ }^{\mathrm{b}}$ Department of Pharmaceutics, School of Pharmaceutical Sciences, Universiti Sains Malaysia, Penang, Malaysia \\ ${ }^{\mathrm{c}}$ Department of Pharmacology, School of Pharmaceutical Sciences, Universiti Sains Malaysia, Penang, Malaysia \\ d School of Pharmacy, Allianze University of Medical Sciences, Allianze University College of Medical Sciences, Kepala Batas, Penang, Malaysia
}

\section{A R T I C L E I N F O}

\section{Article history:}

Received 2 May 2012

Accepted 16 August 2012

Available online 9 March 2013

Keywords:

Glipizide

Precision

Accuracy

\begin{abstract}
A B S T R A C T
A simple, sensitive and selective HPLC method with UV detection for determination of Glipizide in human plasma was developed. Liquid-liquid extraction method was used to extract the drug from the plasma samples. Chromatographic separation of Glipizide was achieved using $\mathrm{C}_{18}$ column (ZORBAX ODS $4.6 \times 150 \mathrm{~mm}$ ). The mobile phase was comprised of $0.01 \mathrm{M}$ potassium dihydrogen phosphate and acetonitrile $(65: 35, \mathrm{v} / \mathrm{v})$ adjusted to $\mathrm{pH} 4.25$ with glacial acetic acid. The analysis was run at a flow rate of $1.5 \mathrm{~mL} / \mathrm{min}$ with an injection volume was $20 \mu \mathrm{L}$. The detector was operated at $275 \mathrm{~nm}$. The calibration curve was linear over a concentration range of $50-1600 \mathrm{ng} / \mathrm{mL}$. Intra-day and inter-day precision and accuracy values were below $15 \%$. The limit of quantification was $50 \mathrm{ng} / \mathrm{mL}$ and the mean recovery was above $98 \%$. Freeze-thaw, short-term, long-term and post-preparative stability studies showed that Glipizide in plasma sample was stable. The method may be successfully applied to analyze the Glipizide concentration in plasma samples for bioavailability and bioequivalence studies.

Copyright $\odot$ 2013, InPharm Association, Published by Reed Elsevier India Pvt. Ltd. All rights reserved.
\end{abstract}

\section{Introduction}

Glipizide is a second generation sulfonylurea ${ }^{1}$ that is used in the treatment of noninsulin-dependent diabetes mellitus. ${ }^{2}$ This compound appears to be the most potent among other sulfonylurea derivatives. ${ }^{3}$ It produces action by blocking potassium channels in the beta cells of islet of langerhans. ${ }^{4}$

Existing literature reveals that analytical methods including Gas Chromatography (GC) $)^{5}$ and High Performance Liquid Chromatographic (HPLC) have been developed for determination Glipizide in human serum ${ }^{6}$ as well as in plasma or urine. ${ }^{7-9} \mathrm{GC}$ method requires derivatization process to form a thermally stable product and thus time consuming. ${ }^{5}$ Besides this, GC method lacks specificity as structurally similar sulphonylureas may form identical derivatives. The HPLC methods reported in the literature ${ }^{6,7}$ have retention time (RT) of 25 and 10.5 min, respectively. High running time is both time and solvent consuming. Therefore, the present study was aimed to develop and validate an efficient new RP-HPLC method for the determination of Glipizide in human plasma that can be subsequently applied to understand its pharmacokinetics in biological system.

\footnotetext{
* Corresponding author.

E-mail address: pharmacist_atif@yahoo.com (M. Atif).
}

\section{Materials and methods}

Glipizide was purchased from Chunghwa Chemical Synthesis and Biotech Co., Ltd., (Taiwan). Hydrochloric acid (35\%) and potassium dihydrogen phosphate were of analytical grades purchased from R \& M (Essex, United Kingdom). Glacial acetic acid and acetonitrile (HPLC grade) were purchased from Merck (Darmstadt, Germany). All other chemicals and reagents were of analytical grade.

Study was approved by board of advance studies and an ethical committee on human use at Department of Pharmacy, The Islamia University of Bahawalpur, Punjab, Pakistan.

\subsection{Instrumentation (specification of HPLC)}

Analysis was performed using Agilent Liquid Chromatography with a pump series 1100, Agilent UV Visible Detector set at $275 \mathrm{~nm}$. A reverse phase system was used consisting of $C_{18}$ column (ZORBAX ODS $4.6 \times 150 \mathrm{~mm}, 5 \mu \mathrm{m}$ ).

\subsection{Chromatographic Conditions}

The mobile phase consisted of $0.01 \mathrm{M}$ potassium dihydrogen phosphate buffer and acetonitrile in a ratio of 65:35 (v/v) adjusted 
to $\mathrm{pH} 4.25$ using glacial acetic acid. It was eluted at a flow rate of $1.5 \mathrm{~mL} / \mathrm{min}$ with an injection volume of $20 \mu \mathrm{L}$. The effluent was monitored at a wavelength of $275 \mathrm{~nm}$ with a run time of $10 \mathrm{~min}$.

\subsection{Preparation of standard drug solutions}

Stock drug solution of $20 \mathrm{ug} / \mathrm{mL}$ was prepared by dissolving $10 \mathrm{mg}$ of Glipizide in $500 \mathrm{~mL}$ of methanol:dichloromethane mixture (10:90). The solution was sonicated for $5 \mathrm{~min}$ and allowed to equilibrate at room temperature. The working standard drug solutions of 300,2500 , and $10,000 \mathrm{ng} / \mathrm{mL}$ were prepared by serial dilution of the stock drug solution. All solutions were stored at $2-8{ }^{\circ} \mathrm{C}$.

\subsection{Preparation of quality control samples}

Three quality control (QC) plasma samples at concentrations of 150,850 , and $1300 \mathrm{ng} / \mathrm{mL}$ were prepared by spiking $500 \mu \mathrm{L}$ blank plasma with appropriate working standard drug solutions.

\subsection{Preparation of standard plasma samples}

Standard plasma samples ranged from 50 to $1600 \mathrm{ng} / \mathrm{mL}$ were prepared by spiking $500 \mu \mathrm{L}$ blank human plasma with suitable working standard drug solutions.

\subsection{Plasma sample treatment}

An aliquot of $500 \mu \mathrm{L}$ of Glipizide spiked plasma samples were measured accurately into $10 \mathrm{~mL}$ glass tubes followed by adding $100 \mu \mathrm{L}$ of $0.05 \mathrm{M}$ HCL to precipitate the plasma protein. The mixture was vortexed for $45 \mathrm{~s}$ and extracted with $3 \mathrm{~mL}$ of toluene and again vortexed for $45 \mathrm{~s}$. Samples were then centrifuged at $4000 \mathrm{rpm}$ for $15 \mathrm{~min}$. The supernatant was collected and transferred to glass tubes and concentrated to dryness using sample concentrator using nitrogen. Dried residue was reconstituted with $75 \mathrm{uL}$ of mobile phase. Plasma sample of $20 \mu \mathrm{L}$ was injected into the chromatographic system.

\subsection{Preparation of calibration curve}

Calibration curve in the range of $50-1600 \mathrm{ng} / \mathrm{mL}$ was constructed to encompass anticipated range of Glipizide concentration in plasma. The extraction and reconstitution of Glipizide was done as per method described earlier. Twenty micro liter of each of the above reconstituted samples were injected and peak area was obtained.

\subsection{Method validation}

The proposed method was validated as with respect to selectivity, linearity, accuracy, precision, recovery, limit of quantification (LOQ), and stability. ${ }^{10}$ The quality control samples at concentrations of 150,850 , and $1300 \mathrm{ng} / \mathrm{mL}$, as well as $50 \mathrm{ng} / \mathrm{mL}$ (LOQ) were used to determine the within-day and between-day precision, accuracy, and recovery of the assay method. The freeze and thaw stability, short-term temperature stability, postoperative stability, and longterm stability were carried out at concentrations of 150 and $1300 \mathrm{ng} / \mathrm{mL}$, whereas the stock solution stability was performed at concentration of $20 \mu \mathrm{g} / \mathrm{mL}$.

\subsection{Selectivity}

The selectivity of the method was determined to ensure the analyte peak was well separated and free from interference of endogenous compounds in the plasma using blank plasma samples spiked with working standard solution.

\subsection{Linearity}

Standard plasma samples with concentration range of 50$1600 \mathrm{ng} / \mathrm{mL}$ were prepared by spiking plasma with different concentration of Glipizide. Standard calibration curve was constructed by plotting the peak area of Glipizide against the corresponding concentrations of standard plasma samples. Linear regression equation and correlation coefficient were determined. The linearity was determined from six standard calibration curves $(n=6)^{10}$ over a concentration range of $50-1600 \mathrm{ng} / \mathrm{mL}$.

\subsection{Precision and accuracy}

For inter-day precision and accuracy, six replicates of each analyte concentrations were injected over 6 consecutive days, whereas for intra-day precision and accuracy, six replicates of each analyte concentrations were injected on the same day. The precision determined at each concentration level should not exceed $15 \%$ of the coefficient of variation (CV) except for LOQ where it should not exceed $20 \%$ of the CV. For accuracy, the mean value should be within $15 \%$ of the actual value except at LOQ where it should not deviate more than $20 \%$.

\subsection{Recovery}

The recovery was calculated by comparing the peak area obtained from the plasma sample after treatment with that of the aqueous drug solution of the corresponding concentration. Each concentration was analyzed six times.

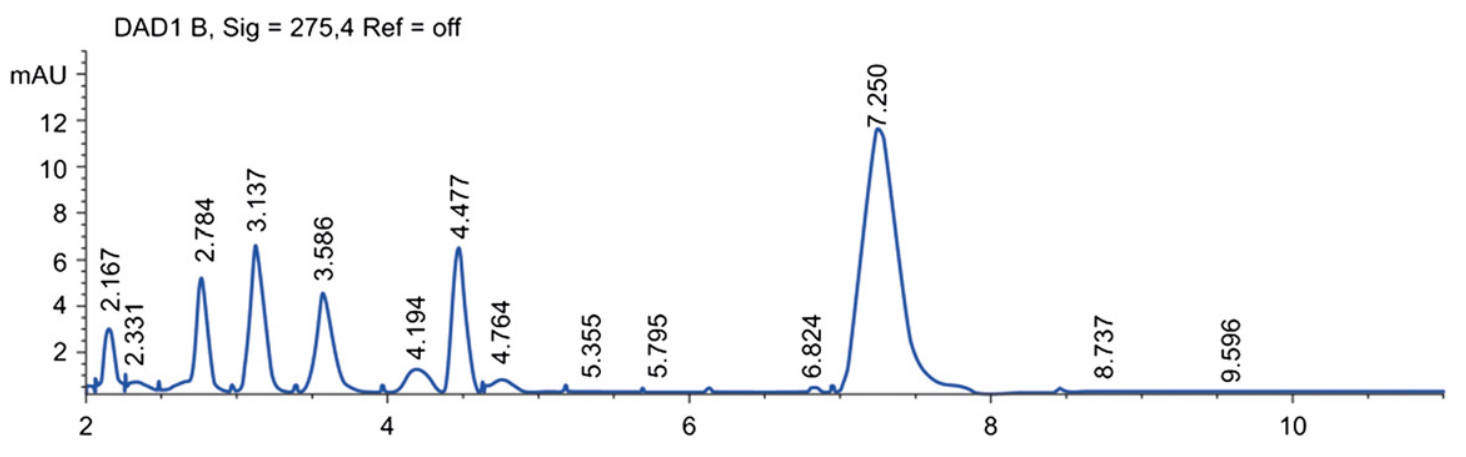

Fig. 1. Chromatogram of Glipizide spiked plasma at $1600 \mathrm{ng} / \mathrm{mL}$. 


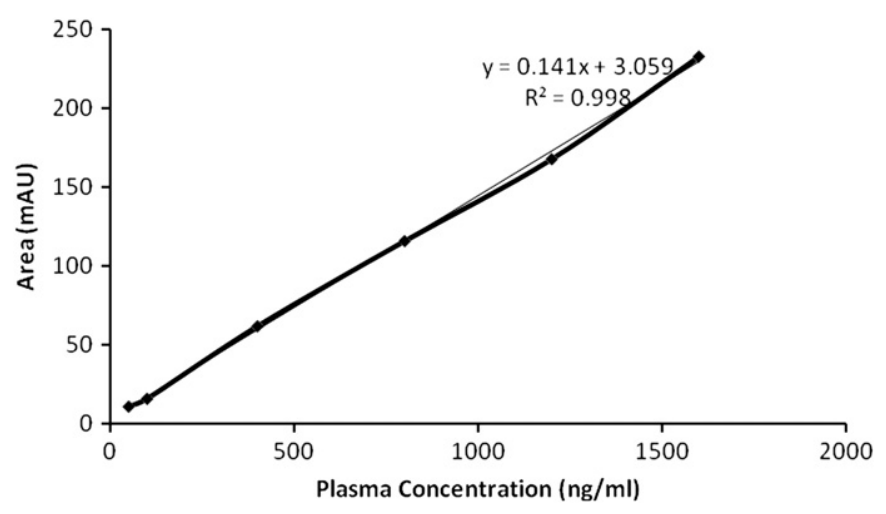

Fig. 2. Standard curve for Glipizide in human plasma.

\subsection{Limit of quantification (LOQ)}

The limit of quantification was determined as the lowest concentration of Glipizide in the standard calibration curve that could be quantified with a value of bias below $20 \%$ and a signal-to-noise ratio of at least 10 .

\subsection{Stability studies}

\subsubsection{Freeze and thaw stability}

The analyte stability was determined after three freeze and thaw cycles. Three aliquots at each of the lower and high concentrations were stored at $-20{ }^{\circ} \mathrm{C}$ for $24 \mathrm{~h}$ and thawed unassisted at ambient room temperature of $25^{\circ} \mathrm{C}$. When completely thawed, the samples were refrozen for $24 \mathrm{~h}$ under the same conditions. The freeze-thaw cycles were repeated two more times and analyzed on the third cycle. ${ }^{10}$

\subsubsection{Short-term stability}

Three aliquots of each of the lower and high concentrations were thawed unassisted at ambient room temperature of $25^{\circ} \mathrm{C}$ and kept at this temperature for $8 \mathrm{~h}$ and analyzed.

\subsubsection{Post-preparative stability}

The stability of the processed samples, including the residence time in the auto-sampler was determined. The stability of Glipizide was assessed over the anticipated run time of $8 \mathrm{~h}$ for the batch size.

\subsubsection{Long-term stability}

Three aliquots of each of the lower and high concentrations of Glipizide stored at $-20^{\circ} \mathrm{C}$ over a period of 3 months were analyzed.

\subsubsection{Stock drug solution stability}

The stability of stock solution was evaluated at an ambient room temperature of $25^{\circ} \mathrm{C}$ for $8 \mathrm{~h}$. The stability was tested by comparing the instrument response to stored stock drug solution with that of freshly prepared solutions.
Table 2

Stability studies of Glipizide (Mean \pm standard deviation, $n=3$ ).

\begin{tabular}{|c|c|c|c|c|c|c|c|c|c|}
\hline \multirow[t]{3}{*}{ Stability study } & \multicolumn{9}{|c|}{ Glipizide concentration $(\mathrm{ng} / \mathrm{mL})$} \\
\hline & \multicolumn{3}{|l|}{150} & \multicolumn{3}{|l|}{1300} & \multicolumn{3}{|l|}{20000} \\
\hline & Mean & SD & RSD & Mean & SD & RSD & Mean & SD & RSD \\
\hline Freeze and thaw & 94.12 & 6.20 & 6.58 & 92.97 & 6.13 & 6.59 & - & - & - \\
\hline Short-term & 93.53 & 7.69 & 8.22 & 90.52 & 4.45 & 4.91 & - & - & - \\
\hline Long-term & 97.06 & 5.29 & 5.45 & 95.59 & 4.68 & 4.89 & - & - & - \\
\hline Post-preparative & 90.70 & 6.04 & 6.65 & 94.44 & 2.52 & 2.66 & - & - & - \\
\hline Stock solution & - & - & - & - & - & - & 99.78 & 0.33 & 0.33 \\
\hline
\end{tabular}

\section{Results and discussion}

\subsection{Method development and sample preparation}

Different organic solvents such as methanol, acetonitrile, and chloroform were used for extraction of Glipizide from human plasma. Among these solvents, toluene was found to be most suitable with high recovery of more than $90 \%$. Internal standard was not required since the method showed high selectivity and sensitivity.

\subsection{Selectivity}

The chromatogram of Glipizide spiked plasma at $16,000 \mathrm{ng} / \mathrm{mL}$ is shown in Fig. 1. It can be seen that the peak of analyte was well resolved and separated.

\subsection{Linearity}

The standard calibration curve was linear over a concentration range of 50-1600 ng/mL. The correlation coefficient $\left(r^{2}\right)$ was 0.9989 [Fig. 2], which is well within acceptable limit. ${ }^{10}$

\subsection{Precision and accuracy}

Both inter- and intra-day precision and accuracy values were well within the acceptable limits [Table 1].

\subsection{Recovery}

The mean recovery values of $93.47 \%( \pm 9.99), 98.57 \%( \pm 7.34)$, $98.68 \%( \pm 6.72)$, and $101.72 \%( \pm 4.67)$ were obtained at $50,150,850$, and $1300 \mathrm{ng} / \mathrm{mL}$, respectively. Average recovery of the analyte was above $98 \%$.

\subsection{Limit of quantification}

The LOQ was $50 \mathrm{ng} / \mathrm{mL}$, which is acceptable to quantify Glipizide in plasma samples.

\section{Table 1}

Intra-day and inter-day precision and accuracy data (mean \pm standard deviation, $n=6$ ).

\begin{tabular}{|c|c|c|c|c|c|c|}
\hline \multirow{2}{*}{$\begin{array}{l}\text { Known concentration } \\
\text { spiked }(\mathrm{ng} / \mathrm{mL})\end{array}$} & \multicolumn{3}{|l|}{ Intra-day } & \multicolumn{3}{|l|}{ Inter-day } \\
\hline & Concentration found (ng/mL) & Precision (\% RSD) & Accuracy (\% error) & Concentration found $(\mathrm{ng} / \mathrm{mL})$ & Precision (\% RSD) & Accuracy (\% error) \\
\hline 50 & $49.50( \pm 4.03)$ & 8.14 & -0.99 & $50.70( \pm 5.42)$ & 10.69 & 1.40 \\
\hline 150 & $144.81( \pm 11.85)$ & 8.18 & -3.46 & $142.13( \pm 10.59)$ & 7.45 & -5.25 \\
\hline 850 & $873.93( \pm 36.79)$ & 4.21 & 2.82 & $839.23( \pm 57.18)$ & 6.81 & -1.27 \\
\hline 1300 & $1316.12( \pm 81.18)$ & 6.17 & 1.24 & $1348.56( \pm 61.90)$ & 4.59 & 3.74 \\
\hline
\end{tabular}




\subsection{Stability study}

The results of short-, long-, and post-preparative stability results were more than $90 \%$, which are well within the acceptable limit. ${ }^{10}$ The stock solution was stable at an ambient room temperature of $25{ }^{\circ} \mathrm{C}$ for more than $8 \mathrm{~h}$ with mean value of $99.78 \%( \pm 0.33)$ at $20,000 \mathrm{ng} / \mathrm{mL}$ [Table 2].

\section{Conclusion}

A rapid, simple, selective, and sensitive HPLC method for estimation of Glipizide in human plasma was successfully developed that can be used in studies aiming at pharmacokinetics of Glipizide.

\section{Conflicts of interest}

All authors have none to declare.

\section{References}

1. Lebovitz HE, Feinglos MN. Mechanism of action of the second-generation sulfonylurea Glipizide. Am J Med. 1983;75:46-54.

2. Ambrogi V, Bloch K, Daturi S, Logemann W, Parenti MA, Tommasini R. New oral anti diabetic drugs. Arzneimittelforschung. 1972;22:542-544.

3. Shuman CR. Glipizide: an overview. Am J Med. 1983;75:55-59.

4. Kavalali G, Tuncel H, Goksel S, Hatemi HH. Hypoglycemic activity of Urtica pilulifera in streptozotocin-diabetic rats. J Ethnopharmacol. 2003;84:241-245.

5. Hartving P, Fagerlund C, Gyllenhaal O. Electron-capture gas chromatography of plasma sulfonylureas after extractive methylation.J Chromatogr. 1980;181:17-24.

6. Wahlin-Boll E, Melander A. A sensitive high performance liquid chromatographic (HPLC) technique for the measurements of Glipizide concentrations in human serum. J Chromatogr. 1979;164:541-546.

7. Emilsson H. High performance liquid chromatographic determination of Glipizide in human plasma and urine. J Chromatogr. 1987;421:319-326.

8. Dhawan S, Singla AK. Performance liquid chromatographic analysis of Glipizide: application to in vitro and in vivo studies. J Chromatogr Sci. 2003;4: 295-300.

9. Atif M, Ahmad M, Qamar-uz-zaman M, et al. Glipizide pharmacokinetics in healthy and diabetic volunteers. Trop J Pharm Res. 2011;10:147-152.

10. FDAUS. Guidance for Industry: Bioanalytical Method Validation. Rockville, MD, USA: US Department of health and human services, US FDA/Center for Drug Evaluation and Research; 2001. 